\title{
Authentic Leadership Questionnaire: invariance between samples of Brazilian and Portuguese employees
}

\author{
Clarissa S. Cervo ${ }^{1,2,3^{*}}$, Lisete dos Santos Mendes Mónico ${ }^{4}$, Nuno Rebelo dos Santos ${ }^{5}$, Claudio Simon Hutz ${ }^{6}$ \\ and Leonor Pais ${ }^{4}$
}

\begin{abstract}
The Authentic Leadership Questionnaire (ALQ) is used to assess authentic leadership (AL). Although ALQ is often used in empirical research, cross-cultural studies with this measure are scarce. Aiming to contribute to filling this gap, this study assesses the invariance of the ALQ measure between samples of Brazilian $(N=1019)$ and Portuguese $(N=842)$ employees. A multi-group confirmatory factor analysis was performed, and the results showed the invariance of the first- and second-order factor models between the Brazilian and Portuguese samples. The results are discussed considering their cultural setting, with the study's limitations and future research directions being pointed out.
\end{abstract}

Keywords: Authentic Leadership Questionnaire, Authentic leadership, Invariance measurement, Cross-cultural study, Multi-group confirmatory factor analysis

\section{Background}

\section{Authentic leadership model}

Conceived by Luthans and Avolio (2003), the authentic leadership (AL) model considers the leader as self-effective, hopeful, resilient, and optimistic. AL is represented by high moral character, altruism, and virtuousness (Avolio and Gardner, 2005). According to Avolio and Gardner (2005), the authentic leader presents the capacity to analyze and make decisions on ethical dilemmas. Walumbwa et al. (2008) add to AL attributes the promotion of a climate of ethical work and development of followers' psychological capacities. The theoretical model of AL is formed of four dimensions. The first, relational transparency, consists of presentation of the leader's genuine "self" rather than a modification with regard to the external context (Ilies et al. 2005). The second, moral and ethics, deals with the leader's attitudes, values, and moral standards (Walumbwa et al. 2008). The third, balanced processing, deals with others' consideration of the leader's deepest information and reflections (Walumbwa et al. 2008). And self-awareness

\footnotetext{
* Correspondence: clacervo@gmail.com

${ }^{1}$ University of Vale do Rio dos Sinos, Avenida Unisinos, 950, CEP: 93.022-750, sala E07 207, São Leopoldo, Brazil

${ }^{2}$ Federal University of Rio Grande do Sul, Porto Alegre, Brazil

Full list of author information is available at the end of the article
}

includes knowledge of self and one's own potential (Avolio and Gardner, 2005).

The Authentic Leadership Questionnaire (ALQ) is a self-administered instrument that assesses the perception of AL (Walumbwa et al. 2008) and has been applied in several cultures and organizational contexts (Gardner et al. 2011). The instrument has two versions, one for leaders to answer about themselves (self-report) and another for employees to rate their leaders.

The ALQ is used in research correlating AL with, for example, working atmosphere (Nelson et al. 2014), team effectiveness (Xiong and Fang, 2014), positive emotions (Ilies et al. 2013), and psychological capital (Laschinger and Fida, 2014). Creativity (Rego et al. 2012) and innovation (Černe et al. 2013) are also variables studied with this measure. Research samples have involved professionals in such different contexts as the navy and army (Borgersen et al. 2014), health (Laschinger and Fida, 2014), and education (Monzani et al. 2014). AL is also studied in institutions of different segments and sizes (Gardner et al. 2011; Hsiung, 2012).

The ALQ has been translated into several languages, and these versions are provided by the authors. Brazilian studies of AL (Lanzoni and Meirelles, 2011; Sobral and Gimba, 2012) have used a Portuguese version of the 
instrument but without validating it and assessing its psychometric qualities (Esper and Cunha, 2015; Fonseca et al. 2015).

The original study of ALQ validation considered an American and Chinese sample (Walumbwa et al. 2008) and attempted to break with the hegemony of North American research into leadership. Walumbwa et al. (2008) tested a one-factor model that explains the 16 items of the ALQ, a first-order model, with a structure of four correlated factors, and a second-order model, in which the four factors are explained by a second-order one. The best adjustment found was for the second-order model (Walumbwa et al. 2008). The psychometric structure of ALQ has been tested in different countries, such as Belgium (Leroy et al. 2012), Spain (Moriano et al. 2011), Portugal (Rego et al. 2012), and Turkey (Müceldili et al. 2013), among others. However, no studies are found on the invariance of this measure for different groups and cultures, as recommended by the International Test Commission (2000). Considering the above, the first research hypothesis is formulated:

Hypothesis 1: The second-order factor model is replicated in a sample of Brazilian employees and a sample of Portuguese employees.

\section{Measurement invariance in authentic leadership studies}

Considering that the ALQ assesses the level of authenticity attributed to the leader, understanding of "being authentic" can be affected by cultural influences (Nyberg and Sveningsson, 2014). For Diddams and Chang (2012), authenticity has distinct mobilizing elements and should therefore not be conceived linearly, as proposed in the initial model. For Milfont and Fischer (2010), cultural idiosyncrasies should be investigated in careful applications of the same measure to distinct groups and individuals. Cross-cultural research examines variations in psychological constructs in different cultural contexts (Rašković and Kržišnik, 2010). This kind of study contributes to advancing organizational research, allowing valid use of an instrument in different groups of individuals (Milfont and Fischer, 2010).

In 1994, Graen and Wakabayashi (1994) stated that leadership studies could not ignore variations in characteristics between countries (Hofstede, 1980, 2001). The AL is always expressed within a specific culture, a specific organization, and a specific society, which leads OwusuBempah et al. (2011) to debate its universal and specific character. That discussion converges with the assumptions of the study of Global Leadership and Organizational Behavior Effectiveness (GLOBE). For Minkov and Blagoev (2012), the current complex organizational scenario means leaders must develop a particular set of skills. In a survey, GLOBE was applied to executives in 62 cultures and societies (House et al. 2004). This identified the main similarities and differences in the contexts analyzed and found three structuring dimensions of the leader's global competences. Those competences, also called the global mindset, unite the leader's intellectual capital, social capital, and psychological capital.

Although criticism of GLOBE is found in the literature (e.g., Hofstede, 2006), House et al. (2004) argue that the model provides a development path of the global mindset for organizations and leaders. Čater et al. (2013) consider that this leadership model contributes to making global objectives and strategies suitable for operation in local markets. Due to the many demands of the globalized market, organizations need flexible leadership (Minkov and Blagoev, 2012). A leader with global skills will adjust better to that situation (House et al. 2004). To strengthen that understanding of leadership, GLOBE imports the concept of psychological capital (psycap), by Luthans (2002). The fact that psycap is one of the ingredients of global leadership suggests that AL itself can also be considered a global leadership.

Nevertheless, despite this more or less universal character of leadership, existing cultural specificities should not be neglected and it is important to refer to them when we approach AL. Lawler and Ashman (2012) understand the formation of authenticity as a continuous process of the individual's interaction, influenced by environmental elements. For Ford and Harding (2011), leaders adjust their authenticity in adapting to a collective context. This view is corroborated by research that identifies a relational and cultural basis for authenticity (Costas and Taheri 2012; Nyberg and Sveningsson, 2014).

Cross-cultural studies indicate that some elements of leadership can be considered universal (Zander and Romani 2004). However, the reasons activating these factors vary according to the values prized in each culture and should therefore be observed in discussions on the subject (Ensari and Murphy, 2003). Exemplifying the potential character of culture in the understanding and expression of authenticity, Zhang et al. (2012) made a study of this model of leadership in Chinese organizations. The results show that Chinese leaders' main source of authenticity lies in the relationship with others. This result reinforces the roles of cultural and social elements in AL. In the same connection, Owusu-Bempah et al. (2014) study the perception of leaders and followers in Ghana and New Zealand as to the formation of AL. They conclude that the leadership model referred to is idiosyncratic but common among cultures.

In this context, Dorfman et al. (2012) argue that when assessing a cultural situation in the framework of a certain theoretical model, other dimensions can emerge. So when a group of people use different expressions to conceptualize the same beliefs, values, behaviors, and attitudes, there may 
be different perceptions in interpreting the items of a measure (Milfont and Fischer 2010). To respond to this challenge, the measurement of equivalence/invariance (ME/I) measures whether the instrument activates similar cognitive, perceptive, and interpretative processes in different groups (Vandenberg and Lance, 2000). That is, identifying whether the measurement invariance confirms that the latent construct can be generalized and is open to analogical interpretation between specific groups (Milfont and Fischer 2010). The non-existence of ME/I can imply differences in the instrument's functioning in the populations studied and not necessarily reflect differences in the model of AL (Sirigatti et al. 2013). In these circumstances, the interpretations and inferences resulting from applying the instrument are affected negatively (Milfont and Fischer 2010).

This study compares the ME/I of ALQ for Brazil and Portugal. It contributes to understanding the universality and specificities of authenticity in the domain of leadership. Brazilian culture was influenced by Portuguese culture, among others, and both countries share the same language and some cultural traits. In the understanding of Hofstede (1980, 2001), common to the two cultures is the dimension of power distance. This form of hierarchy in society, in both countries, reinforces the valuation of individuals' social status. On the other hand, compared to Portugal, Brazil has a culture tending slightly more towards individualism, masculinity, indulgence, and longterm orientation. The dimension of aversion to uncertainty is clearly more expressive in Portugal (Hofstede, 2001).

Research on AL is more advanced in Portugal (Monzani et al. 2014; Rego et al. 2012) than in Brazil (Lanzoni and Meirelles, 2011; Sobral and Gimba, 2012). In this context, this study aims to evaluate the psychometric proprieties and the extent of measurement invariance of the ALQ between samples of Brazilian and Portuguese employees. To do so, the second hypothesis of the study was formulated:

Hypothesis 2: The factor model is invariant between Brazilian and Portuguese employees.

\section{Methods}

\section{Participants}

The sample is made up of a total of 1861 employees in Brazil and Portugal, from organizations of different sectors and sizes. The Brazilian participants are mainly female $(52.9 \%)$. Participants' age is concentrated between 21 and 30 years (34.1\%), and $39 \%$ have been working in the same company over 10 years. The Portuguese sample is also formed predominantly of females $(65.1 \%)$. Participants' age is concentrated between 41 and 50 years (37.1\%), and $43.3 \%$ of them have been employed for over 10 years in the same company. A detailed description of the two samples appears in Table 1.
Table 1 Socio-demographic characterization of the Brazilian and Portuguese samples

\begin{tabular}{|c|c|c|c|c|}
\hline & \multicolumn{2}{|c|}{$\begin{array}{l}\text { Brazil } \\
(n=1019)\end{array}$} & \multicolumn{2}{|c|}{$\begin{array}{l}\text { Portugal } \\
(n=842)\end{array}$} \\
\hline & $N$ & $\%$ & $N$ & $\%$ \\
\hline \multicolumn{5}{|l|}{ Sex } \\
\hline Male & 462 & 45.3 & 292 & 34.7 \\
\hline Female & 539 & 52.9 & 548 & 65.1 \\
\hline No response & 18 & 1.8 & 2 & 0.2 \\
\hline \multicolumn{5}{|l|}{ Age } \\
\hline Under 20 years & 22 & 2.2 & 21 & 2.5 \\
\hline Between 21 and 30 & 347 & 34.1 & 234 & 27.8 \\
\hline Between 31 and 35 & 226 & 22.6 & 82 & 9.7 \\
\hline Between 36 and 40 & 105 & 10.3 & 97 & 11.5 \\
\hline Between 41 and 50 & 192 & 18.8 & 267 & 37.1 \\
\hline Over 51 years & 99 & 9.7 & 139 & 16.5 \\
\hline No response & 28 & 2.7 & 2 & 0.2 \\
\hline \multicolumn{5}{|l|}{ Years in the company } \\
\hline 6 months or less & 51 & 5.9 & 0 & 0 \\
\hline Between 7 months and 1 year & 36 & 3.5 & 97 & 11.5 \\
\hline Between 1 year 1 month and 3 years & 272 & 26.7 & 89 & 10.6 \\
\hline Between 3 years 1 month and 5 years & 144 & 14.1 & 138 & 16.4 \\
\hline Between 5 years 1 month and 10 years & 97 & 9.5 & 147 & 17.5 \\
\hline Over 10 years & 397 & 39 & 365 & 43.3 \\
\hline No response & 22 & 2.2 & 6 & 0.7 \\
\hline \multicolumn{5}{|l|}{ Education } \\
\hline Up to 9 years of education & 35 & 3.4 & 246 & 29.2 \\
\hline From 10 to 12 years & 160 & 15.7 & 281 & 33.4 \\
\hline From 13 to 17 years & 603 & 59.2 & 181 & 21.5 \\
\hline Over 18 years of education & 200 & 19.6 & 128 & 15.2 \\
\hline No response & 21 & 2.1 & 6 & 0.7 \\
\hline \multicolumn{5}{|l|}{ Salary (in euros) } \\
\hline Up to 500 & 457 & 44.8 & 215 & 25.5 \\
\hline Between 501 and 1000 & 375 & 36.8 & 423 & 50.2 \\
\hline Between 1001 and 1500 & 68 & 6.7 & 150 & 17.8 \\
\hline Between 1501 and 2000 & 94 & 9.2 & 34 & 4 \\
\hline Between 2001 and 2500 & 4 & 0.4 & 10 & 1.2 \\
\hline Between 2501 and 3000 & 1 & 0.1 & 2 & 0.2 \\
\hline Between 3001 and 3500 & 0 & 0 & 0 & 0 \\
\hline Between 3501 and 4000 & 0 & 0 & 0 & 0 \\
\hline Over 4000 & 0 & 0 & 0 & 0 \\
\hline No response & 20 & 2.0 & 8 & 1 \\
\hline
\end{tabular}

Both groups contain public and private firms, and the three economic sectors of activity are represented. However, the service sector predominates, since $90.3 \%$ of Brazilian organizations and $38.6 \%$ of Portuguese firms 
in this research belong to this sector. Regarding commerce, $4.5 \%$ of Brazilian and $17.8 \%$ of Portuguese firms in the sample belong to this sector. Industry accounts for $4.1 \%$ of Brazilian and $17.2 \%$ of Portuguese firms. The Portuguese sample contains $25.1 \%$ of organizations with activities of a different nature from those mentioned above.

Concerning the size of organizations, $95.2 \%$ of Brazilian companies in the sample are large and in the Portuguese sample $14.4 \%$ are large. Regarding this aspect, $3 \%$ of Brazilian companies and $60.5 \%$ of Portuguese ones are medium-sized, with $0.8 \%$ of Brazilian companies and $24.3 \%$ of Portuguese ones being small. It should be noted that both samples were selected following the criterion of accessibility and convenience.

\section{Measures}

This study used the ALQ, conceived by Walumbwa et al. (2008). The research project, which the measurement invariance is a part of, was presented to the Mind Garden Institute (Copyright @) 2007 Authentic Leadership Questionnaire by Avolio et al. 2007), and permission for scientific use of the ALQ was obtained. The ALQ was translated and adapted for Portugal by Rego et al. (2012).

The study validating the ALQ for Brazil includes a first stage of translation and back translation (Brislin, 1980). Four bilingual academics were instructed to translate the original English version of the ALQ, observing conceptual similarity. These translations were reviewed by three experts, fluent in English and experienced in the area of organizational psychology. A first version of the ALQ was elaborated and submitted to assessment by two focus groups (leaders and subordinates). Fine-tuning improvements were suggested by the groups concerning idiomatic expressions. An adapted version of the instrument was sent for back translation to two other academics also fluent in English. The same three experts analyzed the translations of the scale comparing them with the original version, defining the Brazilian version of the ALQ. To check the suitability of the instructions and items, a pilot application was carried out, in a sample of 42 followers, 23 women and 19 men. Thirty-eight employees were aged between 21 and 30. Regarding length of service, 35 had been in the same organization between 5 and 10 years. Those characteristics are similar to the sample that participated in the study to validate ALQ for Brazil.

The ALQ is composed of 16 items measured on a fivepoint Likert scale (from 0-never, to 4-frequently, if not always), divided in four dimensions: relational transparency (items 1 to 5, e.g., item 4: Tell you the hard truth), moral and ethics (items 6 to 9, e.g., item 6: Demonstrate beliefs that are consistent with actions), balanced processing (items 10 to 12, e.g., item 11: Analyze relevant data before coming to a decision), and selfawareness (items 13 to 16, e.g., item 16: Show I understand how specific actions impact others). The final scores and those for each dimension were calculated based on the average score of the corresponding items.

This study used the hetero-assessment version of ALQ, in which followers assess their immediate superiors. Participants also answered an inventory of sociodemographic data, with information also being gathered about organizations' size and sector of activity.

\section{Procedures}

Data collection was carried out by duly trained Brazilian and Portuguese researchers. In Brazil, the group of researchers contacted companies and presented the research proposal. With their consent, the study was explained to the employees in the position of followers, and with their agreement, collection on location was arranged. Data collection took place in two ways: on location and online. In the former, collection was arranged previously with the participants and took place in the work environment. To employees in the organizations that opted for online collection, a link to the research was provided via email (using SurveyMonkey). One week later, a reminder was sent to all participants who had not yet answered the questionnaire. In total, data was collected from 1019 employees.

The Portuguese sample was collected through research involving the University of Coimbra and the University of Évora. University students who were duly trained for this specific data collection contacted follower employees in different organizations. The study was explained in detail to each participant and doubts clarified, with collection taking place on location. A total of 842 questionnaires were gathered in.

All employees were informed of the voluntary nature of participation, the confidentiality and anonymity of the information given, and the possibility of withdrawing at any moment. They all signed an informed consent form and were given the researchers' contact number for any clarification required.

\section{Data analysis}

The data were recorded and processed on a database in version 22.0 of SPSS and AMOS. Missing values, all MCAR (completely at random) and under $3 \%$, were substituted by the expectation maximization method (Ibrahim et al. 2005; Kline, 2011). The factorial validity of the ALQ was evaluated with confirmatory factor analysis (CFA) with AMOS (Arbuckle, 2013), maximum likelihood estimation method (Jöreskog and Sörbom 2004). The composite reliability and the average variance extracted for each factor were evaluated as described in Fornell and Larcker (1981). 
In both samples, the skewness and kurtosis of all individual items did not show values excessively distant from those considered suitable for the assumption of normality (Finney and DiStefano, 2006; Kline, 2011): $-0.66 \leq$ sk $\leq-0.21$ and $-0.98 \leq \mathrm{ku} \leq 0.05$ for the Brazilian sample; $-0.58 \leq \mathrm{sk} \leq-0.20$ and $-0.68 \leq \mathrm{ku} \leq-0.02$ for the Portuguese sample. Goodness of fit was evaluated by the indices of $X / \mathrm{df}^{2}$ (acceptable fit $<5$; Arbuckle, 2013; Loehlin, 2004; Wheaton, 1987; $X^{2}$ was irrelevant for $N>500$; Bentler 1990; Schumacker and Lomax, 2010), normed of fit index (NFI; acceptable $>.80$; Bentler and Bonett, 1980; Schumacker and Lomax, 2010), comparative fit index (CFI; good fit $>.90$; Bentler, 1990), parsimony normed fit index (PNFI; very good fit $\geq .80$; Marôco, 2010; Mulaik et al. 1989), standardized root mean square residual (SRMR; appropriate fit <.08; Brown, 2015; Hu and Bentler, 1999), root mean square error of approximation (RMSEA; acceptable fit $<.10$, good fit $<.08$ for Marôco 2010; acceptable fit $<.08$ for Kline 2011, Schumacker and Lomax, 2010, and Steiger, 1990), and Akaike's information criterion (Model AIC; applicable when maximum likelihood estimation is used, Burnham and Anderson, 1998; there is no rule of thumb; the values depend on actual datasets and the model - the model with the lowest AIC value is chosen; Arbuckle, 2013; Burnham et al. 2011). Reliability was estimated by Cronbach's alpha (Cronbach, 1951). Measurement invariance was tested by multi-group confirmatory factor analyses (maximum likelihood estimation); configural, metric, scalar, and full uniqueness invariance values were compared with CFI, RMSEA, and SRMR, since they are not affected by the size of the sample or by the model's complexity (Chen, 2007; Cheung and Rensvold, 2002; Meade et al. 2008).

\section{Results}

Fit of the model proposed by Walumbwa et al. (2008)

CFA was performed in order to examine the first-order (four factors correlated) and the second-order (four firstorder factors determined by a second-order factor) authentic leadership model. Although confirmatory factor analysis performed by Walumbwa et al. (2008) supports a second-order model-"a higher order, multidimensional model of the authentic leadership construct" (Walumbwa et al. 2008, p. 89), we found a better fit for the first-order model (see Table 2 for the fit statistics of the first- and second-order models for the Brazilian and Portuguese samples). Considering all the fit statistics, and despite the strong correlations among the four factors, the first-order factor model showed a better fit in both samples, which led us to pursue the analysis maintaining first and second-order models. No error terms were correlated (based on modification indices). The four factors corresponding to the latent constructs of $\mathrm{AL}$ theory were supported: relational transparency, moral and ethics, balanced processing, and self-awareness. Excluding the value of $X^{2}$, which is considered irrelevant for samples greater than 500 subjects (Bentler, 1990; Schumacker and Lomax, 2010), in a broad sense, the models presented an acceptable fit in both samples. The first-order model showed a better fit in all fit indices. Because the AIC statistic was lower in the firstorder model (Kline, 2011), this model was preferred over the second-order model (Byrne, 2009), although we performed the invariance tests for the first- and second-order models, considering the NFI, CFI, PNFI, and SRMR values.

The standardized regression weights for the confirmatory structural analysis of the alternative model for the Brazilian and Portuguese samples are shown in Table 3. All items have high-standardized regression weights (Tabachnick and Fidell, 2012). For the Brazilian sample, standardized regression weights ranged from .601 to .907 , and the Portuguese one ranged from .535 to .787 . Cronbach alphas and composite reliability (see Table 3 ) were good, since they were above .70 (Hair, Anderson, Tatham, and Black, 1999). Concerning the average extracted variance (AEV), excluding from the Portuguese sample the transparency and moral/ethics dimensions (AEV of .37 and .49, respectively), all the others exceed .50 , ensuring that the explained variance is greater than the residual variance (Bagozzi and Yi, 1988), and all exceed the cutoff value of .40 (Diamantopoulos and Siguaw, 2000) (exception for transparency in the Portuguese sample). In the Portuguese sample, excluding transparency dimension, we are in the presence of discriminant validity, given that the variance extracted from each factor is greater than the values of the squared correlations between each pair of factors (Fornell and Larcker 1981) (see Table 5 for $R^{2}$ ). For

Table 2 Fit statistics of the hypothesized models for Brazil and Portugal

\begin{tabular}{lllllllllllll}
\hline & Sample & Number & $X^{2}$ & $X^{2} / \mathrm{df}$ & $\mathrm{df}$ & $\mathrm{NFI}$ & $\mathrm{CFI}$ & $\mathrm{PNFI}$ & SRMR & RMSEA & $90 \%$ Cl & Model AIC \\
\hline First-order factor model & Brazilian & 1019 & 863.38 & 8.81 & 98 & .931 & .938 & .760 & .041 & .088 & $.082-.093^{*}$ & 939.12 \\
& Portuguese & 842 & 549.78 & 5.61 & 98 & .903 & .919 & .738 & .05 & .074 & $.068-.080^{*}$ & 626.08 \\
\multirow{2}{*}{ Second-order factor model } & Brazilian & 1019 & 929.95 & 9.30 & 100 & .926 & .933 & .771 & .044 & .090 & $.085-.096^{*}$ & 1001.95 \\
& Portuguese & 842 & 569.45 & 5.70 & 100 & .900 & .916 & .750 & .047 & .075 & $.069-.081^{*}$ & 641.45 \\
\hline
\end{tabular}

$X^{2}$ chi-square, $d f$ degrees of freedom, NFI normed fit index, CFI comparative fit index, PNFI parsimony normed fit index, SRMR standardized root mean square residual, RMSEA root mean square error of approximation, $C l$ confidence interval, Model AIC Akaike's information criterion ${ }^{*} p<.001$ 
Table 3 Standardized regression weights (SRW), reliabilities, and average extracted variance (AEV) for first-order and second-order factor models (N Brazil =1019; N Portugal = 842)

\begin{tabular}{|c|c|c|c|c|c|c|c|c|c|c|c|c|c|c|c|}
\hline \multirow{3}{*}{$\begin{array}{l}\text { Factors } \\
\text { Order factor model: }\end{array}$} & \multirow{3}{*}{ Items } & \multicolumn{4}{|l|}{ SRW } & \multicolumn{4}{|l|}{ AEV } & \multicolumn{4}{|c|}{ Composite reliability } & \multicolumn{2}{|c|}{ Cronbach's a } \\
\hline & & \multicolumn{2}{|l|}{$\mathrm{Br}$} & \multicolumn{2}{|l|}{$\mathrm{Pt}$} & \multicolumn{2}{|l|}{$\mathrm{Br}$} & \multicolumn{2}{|l|}{ Pt } & \multicolumn{2}{|l|}{$\mathrm{Br}$} & \multicolumn{2}{|l|}{$\mathrm{Pt}$} & \multirow[t]{2}{*}{$\mathrm{Br}$} & \multirow[t]{2}{*}{$\mathrm{Pt}$} \\
\hline & & $\overline{1 s t}$ & $2 \mathrm{nd}$ & $1 s t$ & $2 n d$ & $\overline{1 s t}$ & 2 2nd & $1 s t$ & $2 n d$ & $\overline{1 s t}$ & $2 n d$ & $1 s t$ & $2 n d$ & & \\
\hline \multirow[t]{5}{*}{ Transparency } & AL1 & .601 & .592 & .592 & .589 & .50 & .50 & .37 & .37 & .83 & .83 & .75 & .75 & .84 & .74 \\
\hline & AL2 & .770 & .776 & .647 & .695 & & & & & & & & & & \\
\hline & AL3 & .814 & .822 & .687 & .651 & & & & & & & & & & \\
\hline & AL4 & .692 & .686 & .535 & .529 & & & & & & & & & & \\
\hline & AL5 & .628 & .614 & .586 & .582 & & & & & & & & & & \\
\hline \multirow[t]{4}{*}{ Moral/ethics } & AL6 & .744 & .743 & .700 & .694 & .63 & .63 & .49 & .49 & .87 & .87 & .79 & .79 & .87 & .79 \\
\hline & AL7 & .814 & .810 & .775 & .775 & & & & & & & & & & \\
\hline & AL8 & .787 & .785 & .649 & .651 & & & & & & & & & & \\
\hline & AL9 & .821 & .827 & .669 & .673 & & & & & & & & & & \\
\hline \multirow[t]{3}{*}{ Balanced processing } & AL10 & .801 & .805 & .603 & .604 & .67 & .66 & .49 & .49 & .86 & .86 & .74 & .74 & .85 & .73 \\
\hline & AL11 & .795 & .797 & .716 & .717 & & & & & & & & & & \\
\hline & AL12 & .849 & .842 & .771 & .770 & & & & & & & & & & \\
\hline \multirow[t]{4}{*}{ Self-awareness } & AL13 & .844 & .822 & .703 & .716 & .74 & .74 & .52 & .52 & .92 & .92 & .81 & .81 & .92 & .81 \\
\hline & AL14 & .822 & .908 & .711 & .787 & & & & & & & & & & \\
\hline & AL15 & .907 & .870 & .787 & .681 & & & & & & & & & & \\
\hline & AL16 & .867 & .841 & .679 & .698 & & & & & & & & & & \\
\hline$A L$ & Transparency & - & .940 & - & .920 & & & & & & & & & & \\
\hline \multirow[t]{3}{*}{ (2nd-order factor) } & Moral/ethics & - & .910 & - & .886 & & & & & & & & & & \\
\hline & Balanced processing & - & .990 & - & .938 & & & & & & & & & & \\
\hline & Self-awareness & - & .957 & - & .899 & & & & & & & & & & \\
\hline
\end{tabular}

$\mathrm{Br}$ Brazil, Pt Portugal, SRW standardized regression weights, AEV average extracted variance

the Brazilian sample, only for self-awareness, the remaining extracted variances were higher than the $R^{2}$ dimensions.

\section{Invariance tests for ALQ}

The results of the invariance analysis are presented in Table 4 for first- and second-order factor models. We compared configural variance (model 1) with three restricted models: metric invariance (model 2), scalar invariance (model 3), and full uniqueness measurement invariance (model 4; Arbuckle, 2013; Byrne, 2009; Marôco, 2010). Firstly, we tested for configural invariance (the free model, unconstrained) running the CFA model for each group separately. Secondly, we tested metric invariance by constraining factor loadings (measurement weights), scalar invariance by constraining measurement weights and intercepts, and full uniqueness measurement invariance by constraining measurement residuals (all parameters constant across groups; Arbuckle, 2013).

To test the fit of each measurement invariance model, we turn to the values of the CFI and the RMSEA, since, in general, they are not influenced by the size of the sample nor by the complexity of the model and are not associated with global adjustment measures (Chen, 2007;
Cheung and Rensvold, 2002). As can be seen in Table 4, CFI and RMSEA decreased by .001 from configural to metric invariance for both first- and second-order models, which is suitable for invariance, considering the guidelines for RMSEA and for CFI-changes in RMSEA of $\geq .010$ to .015 and in CFI of $\leq-.005$ to -.010 (Chen, 2007) or changes in CFI $\leq-.001$ (Cheung and Rensvold, 2002) or $\leq-.002$ to -.008 (Meade et al. 2008), indicate invariance. Additionally, considering that a change in SRMR of $\geq .025$ to .030 is recommended for invariance testing of factor loadings (Chen, 2007) and our differences were only of $\triangle \mathrm{SRMR}=.003$ for the first-order model and $\triangle \mathrm{SRMR}=.002$ for the second-order model, metric invariance was shown.

The differences in RMSEA and CFI between scalar and metric invariance were $\triangle \mathrm{RMSEA}=.005$ and $\triangle \mathrm{CFI}=-.020$ for both first- and second-order models; these differences can also be accepted for invariance since, according to Chen (2007), for a cutoff point of .05, only a value equal to or less than -.005 in the CFI associated with a value equal to or greater than .010 in the RMSEA shows noninvariance (for a cutoff point of .01, change of $<-.010$ for CFI and >.015 for RMSEA). Also, considering SRMR, a 
Table 4 Fit statistics for measurement of invariance for first-order and second-order factor models $(N=1861)$

\begin{tabular}{|c|c|c|c|c|c|c|c|c|c|c|c|c|c|c|c|c|c|c|c|c|c|c|c|c|c|c|}
\hline \multirow{2}{*}{$\begin{array}{l}\text { Model } \\
\text { Order factor model: }\end{array}$} & \multicolumn{2}{|l|}{$x^{2}$} & \multicolumn{2}{|l|}{$d f$} & \multicolumn{2}{|l|}{$x^{2} / d f$} & \multicolumn{2}{|l|}{$\mathrm{NFI}$} & \multicolumn{2}{|l|}{$\mathrm{CFI}$} & \multicolumn{2}{|l|}{$\Delta C F I$} & \multicolumn{2}{|l|}{ PNFI } & \multicolumn{2}{|c|}{ SRMR } & \multicolumn{2}{|c|}{$\Delta S R M R$} & \multicolumn{2}{|c|}{ RMSEA } & \multicolumn{2}{|c|}{$\triangle$ RMSEA } & \multicolumn{2}{|l|}{$90 \% \mathrm{Cl}$} & \multicolumn{2}{|c|}{ Model AIC } \\
\hline & $1 s t$ & 2nd & $1 s t$ & 2nd & $1 s t$ & 2 2nd & $1 s t$ & $2 n d$ & $1 s t$ & $2 n d$ & $1 s t$ & 2nd & $1 s t$ & $2 n d$ & $1 s t$ & $2 n d$ & $1 s t$ & $2 n d$ & $1 s t$ & 2nd & $1 \mathrm{st}$ & 2nd & $1 \mathrm{st}$ & 2nd & $1 \mathrm{st}$ & 2nd \\
\hline \multicolumn{27}{|l|}{ Invariance } \\
\hline 1. Configural & $1413.2^{*}$ & $1499.4^{*}$ & 196 & 200 & 7.21 & 7.50 & .922 & .918 & .932 & .928 & - & - & .753 & .765 & .045 & .047 & - & - & .058 & .059 & - & - & $.055-.061^{*}$ & $.056-.062^{*}$ & 1629.2 & 1707.4 \\
\hline 2. Metric & $1443.0^{*}$ & $1530.4^{*}$ & 208 & 212 & 6.94 & 7.22 & .921 & .916 & .931 & .927 & -.001 & -.001 & .798 & .809 & .048 & .049 & .003 & .002 & .057 & .058 & -.001 & -.001 & $.054-.059^{*}$ & $.055-.061^{*}$ & 1635.0 & 1714.4 \\
\hline 3. Scalar & $1820.8^{*}$ & $1901.8^{*}$ & 224 & 228 & 8.13 & 8.34 & .900 & .896 & .911 & .907 & -.020 & -.020 & .840 & .851 & .048 & .049 & .000 & .000 & .062 & .063 & .005 & .005 & $.059-.065^{*}$ & $.060-.065^{*}$ & 1980.8 & 2053.8 \\
\hline $\begin{array}{l}\text { 4. Full uniqueness } \\
\text { measurement }\end{array}$ & $2214.4^{*}$ & $2290.2^{*}$ & 250 & 252 & 8.86 & 9.09 & .878 & .874 & .891 & .887 & -.020 & -.020 & .915 & .918 & .105 & .105 & .057 & .056 & .065 & .066 & .003 & .003 & $.063-.068^{*}$ & $.063-.068^{*}$ & 2322.4 & 2394.2 \\
\hline
\end{tabular}


change of $\geq .005$ to .010 is recommended for intercept level and residual variance tests (Chen, 2007), where our difference from scalar to metric invariance was $\triangle \mathrm{SRMR}=.000$, strengthening scalar invariance.

Full uniqueness measurement invariance (all parameters equal across groups) is rarely tested (Raju et al. 2002), because "this scenario of invariant measurement residuals is considered too restrictive and, in general, invariance analysis does not require residual invariance" (Marôco, 2010, p. 288). Despite this, for the first- and second-order models, the $\triangle$ CFI were -.020 and the $\triangle$ RMSEA were .003 , which also indicates invariance for these higher order models, since non-invariance exists only when the decrement in model fits exceeds RMSEA $\geq .010$ and $\mathrm{CFI} \geq-.005$ (Chen, 2007), which does not occur in either the first- or second-order model.

\section{Authentic leadership model: comparison between Brazil and Portugal}

The descriptive statistics and inter-correlations between the dimensions of the ALQ are indicated in Table 5. Inter-correlations of a greater magnitude are found for the Brazilian sample. To analyze the differences in AL according to participants' nationality, a multivariate analysis of the variance (MANOVA, general linear model procedure) was performed, taking as the independent variable (IV) nationality ( $1=$ Portugal; $2=$ Brazil $)$ and as dependent variables (DV) each dimension of AL. Analysis of the multivariate test indicates a significant effect on the difference of perception of AL between the Brazilian and Portuguese samples, Wilks $\Lambda=0.931, F(4,1856)=34.53$, $\eta_{\mathrm{p}}^{2}=.069, p<.001$. The results of the univariate tests are presented in Table 5. It can be observed that we only record two differences of a low magnitude, one concerning moral and ethics (effect size $\eta^{2}=0.4 \%$ ) and the other with self-awareness $\left(\eta^{2}=2.5 \%\right)$.

\section{Discussion}

The main aim of this study was to analyze the ME/I of the ALQ between Brazil and Portugal. Considering the hypotheses formulated, we conclude both were supported. Indeed, the first- and second-order factor models were found to be reproduced in the samples of Brazilian and Portuguese employees. However, the first-order model showed a slightly better fit. The factor models we validated were shown to be equally invariant between the two samples, whether concerning the first- or second-order model. These results are aligned with the Walumbwa et al. (2008) model, strengthening the use of the instrument in Brazil and Portugal and making comparison possible (Milfont and Fischer 2010).

As stated above, Brazil and Portugal have cultural similarities and differences (Hofstede, 2001). According to Hofstede (2001), Brazilian culture is more individualistic and has higher masculinity, long-term orientation, and indulgency than Portuguese culture. Portugal is comparatively higher in uncertainty avoidance. Both cultures are high and similar regarding power distance, organizational hierarchy and status are prized, and when the leader shows authenticity, that is highlighted by the followers (Avolio and Gardner, 2005; Hofstede, 2001). Owusu-Bempah et al. (2014) state that in the AL model there are both idiosyncratic and common elements. That is in accordance with the GLOBE approach since it considers that the leader has to develop global abilities and enough flexibility to enable him or her to lead in the local markets (Čater et al. 2013; Minkov and Blagoev, 2012).

Our results are also in accordance with the AL literature, since research in different countries has shown the ALQ model has acceptable fit (Moriano et al. 2011; Rego et al. 2012; Leroy et al. 2012). Several variables are found to be related to $\mathrm{AL}$, such as team effectiveness (Xiong and Fang, 2014), positive emotions (Ilies et al. 2013), and innovation (Černe et al. 2013), in different contexts (e.g., healthcare, Laschinger and Fida 2014, and education, Monzani et al. 2014). Overall, our results together with those studies strengthen the applicability and wide scope of the AL model (Walumbwa et al. 2008).

Analysis of the AL model for both samples indicates the same dimensional structure, although the explanatory power of the dimensions differs between the groups. The dimension with highest explanatory power is self-awareness. The AL model proposes that one of

Table 5 Descriptive statistics and inter-correlations between dimensions of $\mathrm{AL}\left(r^{2}\right.$ in parenthesis), univariate tests, and effect size $\left(\eta^{2}\right)$ for the Brazilian and Portuguese samples

\begin{tabular}{|c|c|c|c|c|c|c|c|c|c|c|c|c|}
\hline \multirow{3}{*}{$\begin{array}{l}\text { Dimension of authentic } \\
\text { leadership }\end{array}$} & \multicolumn{10}{|c|}{ Nationality } & \multirow{3}{*}{$F(1,1859)$} & \multirow{3}{*}{$\eta^{2}$} \\
\hline & \multicolumn{5}{|c|}{ Brazil $(n=1019)$} & \multicolumn{5}{|c|}{ Portugal $(n=842)$} & & \\
\hline & $M$ & SD & 1 & 2 & 3 & $M$ & SD & 1 & 2 & 3 & & \\
\hline Transparency (1) & 2.6 & .84 & & & & 2.7 & .75 & & & & 0.59 & .000 \\
\hline Moral/ethics (2) & 2.1 & .74 & $.781^{*}(.61)$ & & & 2.1 & .63 & $.664^{*}(.44)$ & & & $6.90^{*}$ & .004 \\
\hline Balanced processing (3) & 2.5 & .99 & $.750^{*}(.56)$ & $.770^{*}(.59)$ & & 2.5 & .86 & $.631^{*}(.40)$ & $.649^{*}(.42)$ & & 0.05 & .000 \\
\hline Self-awareness (4) & 2.3 & 1.05 & $.759 *(.58)$ & $.758^{*}(.57)$ & $.859 *(.74)$ & 2.6 & .80 & $.647^{*}(.42)$ & $.623^{*}(.39)$ & $.690^{*}(.48)$ & $47.77^{* *}$ & .025 \\
\hline
\end{tabular}

${ }^{*} p<.01 ;{ }^{* *} p<.001$ 
the precedents of AL includes the capacity of balance between perception of self and the influences of the external context (Walumbwa et al. 2008). This construct being what most explains the model in the two samples reinforces the theoretical grounding and understanding that exercising authenticity includes the leader's selfknowledge (Avolio and Gardner, 2005).

The second dimension with highest explanatory effect corresponds to balanced processing, and its relevance concerns the essence of the leader-subordinate relationship (Ilies et al. 2013). Moral and ethics, the third most explanatory dimension, focuses on leaders' values, their beliefs, and moral standards. The prominence of this dimension, in both samples, reinforces how much subordinates perceive the leader's morality, observing an alignment between his/her discourse and action (Avolio and Gardner, 2005). The last explanatory factor of the model in both groups is relational transparency. To some extent, this dimension is strengthened in the interaction with the others. For the relationship between leader and subordinates to be solid and clear, leaders must initiate the leadership process knowing themselves well (self-awareness). It will then be possible to develop open leadership, coming closer to employees through the ease of sharing (balanced processing). In daily socializing and faced with organizational challenges, subordinates need to find coherence between their leader's discourse and practice (moral and ethics). This set of conditions allows leaders to form transparent relationships with their subordinates (Avolio and Gardner, 2005). When authentic leaders are not afraid to expose themselves, levels of trust are developed with subordinates. This trust promotes greater sharing of information and knowledge, creating a feeling of partnership and making work contexts more human (Avolio and Gardner, 2005; Ilies et al. 2013; Walumbwa et al. 2008).

\section{Limitations}

One limitation of this research lies in comparing the invariance of the ALQ in only two cultures. Considering cultural differences in studies on leadership is relevant in understanding how authenticity is developed and perceived in different nationalities. This study sought to contribute to cross-cultural research into AL, including a Brazilian sample, and also intended to address the shortage of studies in Latin-American countries. However, it is recommended that future studies extend the number of cultures analyzed.

A second limitation of this study concerns analysis of the ALQ only in the hetero-assessment version. The authors formulated a self-assessment version which was not considered in this study. The purpose of this research was to deepen understanding of how subordinates perceive authenticity in their superiors. But this aim should be extended and deepened with samples of leaders. Finally, we highlight the need to validate the results obtained here in longitudinal studies.

\section{Conclusions}

This study supports analysis of the invariance of the ALQ in Brazilian and Portuguese samples. The instrument was found to be invariant and therefore validated for intra- and inter-group identification of leadership authenticity as perceived by subordinates. The work carried out contributes to meeting the growing need for cross-cultural research into the dimensions forming the construct of authentic leadership. In addition, it contributes to providing the academic and business community with a measure that can be used in assessing authentic leadership and that has adequate psychometric proprieties. By sharing the importance of this model of leadership in the organizational context, we hope the study carried out will stimulate and encourage future cross-cultural research with the AL model. For all the reasons presented above, we conclude on the invariance of the ALQ between Brazilian and Portuguese employees.

\section{Authors' contributions}

CSC conceived of the study and design, contributed to the acquisition of the Brazilian data, participated in the analysis and interpretation of the data, and coordinated the manuscript draft. LSMM contributed to conception and design and acquisition of the Portuguese data, participated in the analysis, and was involved in the drafting and revising of the manuscript. NRS contributed to conception and design and acquisition of the Portuguese data. He was involved in revising critically the manuscript. CSH contributed to conception and design and acquisition of the Brazilian data. He was involved in revising critically the manuscript. LP contributed to conception and design and acquisition of the Portuguese data, participated in the interpretation of the data, and was involved in the drafting and revising of the manuscript. All authors read and approved the final manuscript.

\section{Authors' information}

Clarissa Socal Cervo_-Professor at the University of Vale do Rio dos Sinos, Brazil, teaching in work and organizational psychology. Research interests include positive psychology, leadership, organizational culture, and cooperation. Lisete dos Santos Mendes Mónico_-Professor at the University of Coimbra. Member of the Center for Research and Intervention in Social Psychology, Center for Opinion Studies and Surveys and Institute of Cognitive

Psychology, Vocational and Social Development. Research in the field of Social and Organizational Psychology.

Nuno Rebelo dos Santos_-Professor at the University of Évora, Portugal, teaching in work and organizational psychology and in research methods. His main research areas are leadership, performance, cooperation, and ethics. Claudio Simon Hutz-Full professor at Federal University of Rio Grande do Sul, Brazil. His research interests include Positive Psychology, Psychological Assessment, Psychometry, Personality, and Social Development. Leonor Pais-Professor at the University of Coimbra and Porto Business School, Portugal. Portuguese Coordinator of the European WOP-P Master. Research interests focused on knowledge management, HRM, cooperation, and decent work.

\section{Competing interests}

The authors declare that they have no competing interests.

\section{Author details}

'University of Vale do Rio dos Sinos, Avenida Unisinos, 950, CEP: 93.022-750, sala E07 207, São Leopoldo, Brazil. Federal University of Rio Grande do Sul, Porto Alegre, Brazil. ${ }^{3}$ CAPES Foundation, Ministery of Education of Brazil, São 
Leopoldo, Brazil. ${ }^{4}$ Faculty of Psychology and Educational Sciences, University of Coimbra, Coimbra, Portugal. ${ }^{5}$ School of Social Sciences, University of Évora, Évora, Portugal. ${ }^{6}$ Department of Psychology, Federal University of Rio Grande do Sul, Rio Grande do Sul, Brazil.

\section{Received: 16 December 2015 Accepted: 15 August 2016} Published online: 30 August 2016

\section{References}

Arbuckle, J. L. (2013). Amos 22 user's guide. Chicago, IL: SPSS Inc.

Avolio, B., \& Gardner, W. (2005). Authentic leadership development: getting to the root of positive forms of leadership. The Leadership Quarterly, 16, 315-338. doi:10.1016/j.leaqua.2005.03.001.

Avolio, B., Gardner, W., \& Walumbwa, F. (2007). Authentic Leadership Questionnaire (www.document). Available at: http://www.mindgarden.com/69-authenticleadership-questionnaire. Accessed 6 de Agosto 2013.

Bagozzi, R. P., \& Yi, Y. (1988). On the evaluation of structural equation models. Journal of the Academy of Marketing Science, 16, 74-94.

Bentler, P. (1990). Quantitative methods in psychology: comparative fit indexes in structural models. Psychological Bulletin, 107, 238-246.

Bentler, P. M., \& Bonett, D. G. (1980). Significance tests and goodness-of-fit in the analysis of covariance structures. Psychological Bulletin, 88, 588-606.

Borgersen, H., Hystad, S., Larsson, G., \& Eid, J. (2014). Authentic leadership and safety climate among seafarers. Journal of Leadership \& Organizational Studies, 21(4), 394-402. doi:10.1177/1548051813499612.

Brislin, R. (1980). Translation and content analysis of oral and written materials. In H. C. Triandis \& J. W. Berry (Eds.), Handbook of cross-cultural psychology (Vol. 2, pp. 389-444). Boston: Allyn \& Bacon.

Brown, T. A. (2015). Confirmatory factor analysis for applied research (2nd ed.). New York: Guilford Press.

Burnham, K. P., \& Anderson, D.R. (1998). Model selection and inference: a practical information-theoretic approach. New York: Springer-Verlag.

Burnham, K. P., Anderson, D. R., \& Huyvaert, K. P. (2011). AIC model selection and multimodel inference in behavioral ecology: some background, observations, and comparisons. Behavioral Ecology and Sociobiology, 65, 23-35. doi:10.1007/ s00265-010-1029-6.

Byrne, B. M. (2009). Structural equation modeling with AMOS: basic concepts, applications, and programming (2nd ed.). New York: Routledge.

Čater, T., Lang, R., \& Szabo, E. (2013). Values and leadership expectations of future managers: theoretical basis and methodological approach of the GLOBE student project. Journal for East European Management Studies, 4, 442-462.

Černe, M., Jaklič, M., \& Škerlavaj, M. (2013). Authentic leadership, creativity, and innovation: a multilevel perspective. Leadership, 9(1), 63-85. doi:10.1177/ 1742715012455130

Chen, F. E. (2007). Sensitivity of goodness of fit indexes to lack of measurement invariance. Structural Equation Modeling, 14, 464-504. doi:10.1080/ 10705510701301834.

Cheung, G. W., \& Rensvold, R. B. (2002). Evaluating goodness-of-fit indexes for testing measurement invariance. Structural Equation Modeling, 9, 233-255.

Costas, J., \& Taheri, A. (2012). The return of the primal father' in postmodernity? A Lacanian analysis of authentic leadership. Organization Studies, 33(9), 1195-1216. doi:10.1177/0170840612448157.

Cronbach, L. J. (1951). Coefficient alpha and the internal structure of tests. Psychometrika, 6(13), 297-334.

Diamantopoulos, A., \& Siguaw, J. A. (2000). Introducing to Lisrel: a guide for the uninitiated. London: Sage.

Diddams, M., \& Chang, G. (2012). Only human: exploring the nature of weakness in authentic leadership. The Leadership Quarterly, 23, 593-603. doi:10.1016/j. leaqua.2011.12.010

Dorfman, P., Mansour Javidan, M., Hanges, P., Dastmalchian, A., \& House, R. (2012). GLOBE: a twenty year journey into the intriguing world of culture and leadership. Journal of World Business, 47, 504-518. doi:10.1016/j.jwb.2012.01.004.

Ensari, N., \& Murphy, S. (2003). Cross-cultural variations in leadership perceptions and attribution of charisma to the leader. Organizational Behavior Human Decision Process, 92, 52-66.

Esper, A., \& Cunha, C. (2015). Liderança Autêntica: Uma revisão integrativa. Navus Revista de Gestão e Tecnologia, 5(2), 60-72.

Finney, S. J., \& DiStefano, C. (2006). Non-normal and categorical data in structural equation modeling. In G. R. Hancock \& R. O. Mueller (Eds.), Structural equation modeling: a second course (pp. 269-314). Greenwich, CT: Information Age Publishing.
Fonseca, A., Porto, J., \& Borges-Andrade, J. (2015). Liderança: Um retrato da produção científica brasileira. Revista de Administração Brasileira, 19(3), 290-310. doi:10.1590/1982-7849rac20151404.

Fornell, C., \& Larcker, D. F. (1981). Evaluating structural equation models with unobservable variables and measurement error. Journal of Marketing Research, 18(1), 39-50.

Ford, J., \& Harding, N. (2011). The impossibility of the 'true self' of authentic leadership. Leadership, 7(4), 463-479. doi:10.1177/1742715011416894.

Gardner, W., Cogliser, C., Davis, K., \& Dickens, M. (2011). Authentic leadership: a review of the literature and research agenda. The Leadership Quarterly, 22, 1120-1145.

Graen, G. B., \& Wakabayashi, M. (1994). Cross-cultural leadership making: bridging American and Japanese diversity for team advantage. In H. C. Triandis, M. D. Dun- nette, \& L. M. Hough (Eds.), Handbook of industrial and organizational psychology (pp. 414-446). Chicago: Rand-McNally.

Hair, J. F., Jr., Anderson, R. E., Tatham, R. L., \& Black, W. C. (1999). Análisis multivariante. Madrid, España: Prentice Hall International.

Hofstede, G. (1980). Motivation, leadership and organization: do American theories apply abroad? Organizational Dynamics, 9(1), 42-63.

Hofstede, G. (2001). Culture's consequences: comparing values, behaviors, institutions, and organizations across nations (2nd ed.). Thousand Oaks, CA: Sage.

Hofstede, G. (2006). What did GLOBE really measure? Researchers' minds versus respondents' minds. Journal of International Business Studies, 37, 882-896.

House, R. J., Hanger, P. J., Javidan, M., Dorfman, P. W., \& Gupta, V. (2004). Culture, leadership, and organizations: the GLOBE study of 62 societies. Thousand Oaks, CA: Sage.

Hsiung, H. (2012). Authentic leadership and employee voice behavior: a multilevel psychological process. Journal of Business Ethics, 107, 349-361. doi:10.1007/s10551-011-1043-2.

Hu, L., \& Bentler, P. M. (1999). Cutoff criteria for fit indexes in covariance structure analysis: conventional criteria versus new alternatives. Structural Equation Modeling, 6, 1-55.

Ibrahim, J. G., Chen, M. H., Lipsitz, S. R., \& Herring, A. H. (2005). Missing-data methods for generalized linear models: a comparative review. Journal of the American Statistical Association, 100, 332-346.

Ilies, R., Curseu, P., Dimotakis, N., \& Spitzmuller, M. (2013). Leaders' emotional expressiveness and their behavioural and relational authenticity: effects on followers. European Journal of Work and Organizational Psychology, 22(1), 4-14. doi:10.1080/1359432X.2011.626199.

\|lies, R., Morgeson, F., \& Nahrgang, J. (2005). Authentic leadership and eudaemonic well-being: understanding leader-follower outcomes. The Leadership Quarterly, 16, 373-394. doi:10.1016/j.leaqua.2005.03.002.

ITC_International Test Commission. (2000). Guidelines on test use. Taken from, http://www.intestcom.org/files/guideline_test_use_portuguese_brazil.pdf.

Jöreskog, K. G., \& Sörbom, D. (2004). LISREL 8.7 for Windows [Computer Software]. Lincolnwood, IL: Scientific Software International, Inc.

Kline, R. B. (2011). Principles and practice of structural equation modeling (3rd ed.). New York: The Guilford Press.

Lanzoni, G., \& Meirelles, B. (2011). Leadership of the nurse: an integrative literature review. Revista latino-americana de enfermagem, 19(3), 651-658.

Laschinger, H., \& Fida, R. (2014). New nurses burnout and workplace wellbeing: the influence of authentic leadership and psychological capital. Burnout Research, 1, 19-28. doi:10.1016/j.burn.2014.03.002.

Lawler, J., \& Ashman, I. (2012). Theorizing leadership authenticity: a Sartrean perspective. Leadership, 8(4), 327-344. doi:10.1177/1742715012444685.

Leroy, H., Palanski, M. E., \& Simons, T. (2012). Authentic leadership and behavioral integrity as drivers of follower commitment and performance. Journal of Business Ethics, 107, 255-264. doi:10.1007/s10551-011-1036-1.

Loehlin, J. C. (2004). Latent variable models: an introduction to factor, path, and structural analysis (4th ed.). Hillsdale, NJ: Lawrence Erlbaum Associates.

Luthans, F. (2002). The need for and meaning of positive organizational behavior. Journal of Organizational Behavior, 23, 695-706. doi:10.1002/job.165.

Luthans, F., \& Avolio, B. J. (2003). Authentic leadership development. In K. S. Cameron, J. Dutton, \& R. E. Quinn (Eds.), Positive organizational scholarship (pp. 241-261). San Francisco, CA: Berrett-Koehler.

Marôco, J. (2010). Análise de equações estruturais: Fundamentos teóricos, software \& aplicações. Pêro Pinheiro: Report Number.

Meade, A. W., Johnson, E. C., \& Braddy, P. W. (2008). Power and sensitivity of alternative fit indices in tests of measurement invariance. Journal of Applied Psychology, 93, 568-592.

Milfont, T. L., \& Fischer, R. (2010). Testing measurement invariance across groups: applications in cross-cultural research. International Journal of Psychological Research, 3, 111-121. 
Minkov, M., \& Blagoev, V. (2012). What do project GLOBE's cultural dimensions reflect? An empirical perspective. Asia Pacific Business Review, 18(1), 27-43. doi:10.1080/13602381.2010.496292.

Monzani, L., Ripoll, P., \& Peiró, J. (2014). Followers' agreeableness and extraversion and their loyalty towards authentic leadership. Psicothema, 26(1), 69-75. doi:10.7334/psicothema2013.67.

Moriano, J. A., Molero, F., \& Mangin, J.-P. L. (2011). Liderazgo auténtico: Concepto y validación del cuestionario ALQ en España. Psicothema, 23(2), 336-341.

Mulaik, S. A., James, L. R., Van Alstine, J., Bennett, N., Lind, S., \& Stilwell, C. D. (1989). Evaluation of goodness-of-fit indices for structural equation models. Psychological Bulletin, 105, 430-435

Müceldili, B., Turan, H., \& Erdil, O. (2013). The Influence of authentic leadership on creativity and innovativeness. Procedia - Social and Behavioral Sciences, 99, 673-681. doi:10.1016/j.sbspro.2013.10.538.

Nelson, K., Boudrias, J., Brunet, L., Morin, D., Civita, M., Savoie, A., \& Alderson, M. (2014). Authentic leadership and psychological well-being at work of nurses: the mediating role of work climate at the individual level of analysis. Burnout Research, 1, 90-101. doi:10.1016/j.burn.2014.08.001.

Nyberg, D., \& Sveningsson, S. (2014). Paradoxes of authentic leadership: leader identity struggles. Leadership, 10(4), 437-455. doi:10.1177/1742715013504425.

Owusu-Bempah, J., Addison, R., \& Fairweather, J. (2011). Does follower subjectivity matter in defining authentic leadership? A call for qualitative research. Asia Pacific Journal of Business and Management, 2(2), 1-25.

Owusu-Bempah, J., Addison, R., \& Fairweather, J. (2014). Commonalities and specificities of authentic leadership in Ghana and New Zealand. Educational Management Administration \& Leadership, 1-21. doi:10.1177/1741143213502198

Raju, N. S., Laffittee, L. J., \& Byrne, B. M. (2002). Measurement equivalence: a comparison of methods based on confirmatory factor analysis and item response theory. Journal of Applied Psychology, 87, 517-529. doi:10.1037// 0021-9010.87.3.517.

Rašković, M., \& Kržišnik, S. (2010). Cross-cultural comparison of leadership practices from Slovenia and Portugal using the Globe Research Program Methodology. Portuguese Journal of Management Studies, 15(1), 13-33.

Rego, A., Sousa, F., Marques, C., \& Cunha, M. P. (2012). Authentic leadership promoting employees' psychological capital and creativity. Journal of Business Research, 65, 429-437. doi:10.1016/j.jbusres.2011.10.003.

Schumacker, R. E., \& Lomax, R. G. (2010). A beginner's guide to structural equation modeling (3rd ed.). Mahwah, N.J.: Lawrence Erlbaum Associates.

Sirigatti, S., Penzo, I., lani, L., Mazzeschi, A., Hatalskaja, H., Giannetti, E., \& Stefanile, C. (2013). Measurement invariance of Ryff's psychological well-being scales across Italian and Belarussian students. Social Indicators Research, 113, 67-80. doi:10.1007/s11205-012-0082-0.

Sobral, F., \& Gimba, R. (2012). As prioridades axiológicas do líder autêntico: Um estudo sobre valores e liderança. Revista de Administração Mackenzie, 13(3), $1518-6776$.

Steiger, J. H. (1990). Structural model evaluation and modification: an interval estimation approach. Multivariate Behavioral Research, 25, 173-180.

Tabachnick, B. G., \& Fidell, L. S. (2012). Using multivariate statistics (6th ed.) Boston: Allyn and Bacon.

Vandenberg, R. J., \& Lance, C. E. (2000). A review and synthesis of the measurement invariance literature: suggestions, practices, and recommendations for organizational research. Organizational Research Methods, 3(1), 4-69. doi:10.1177/109442810031002.

Wheaton, B. (1987). Assessment of fit in overidentified models with latent variables. Sociological Methods and Research, 16, 118-154.

Walumbwa, F., Avolio, B., Gardner, W., Wernsing, T., \& Peterson, S. (2008). Authentic leadership: development and validation of a theory-based measure. Journal of Management, 34, 89-126.

Xiong, H., \& Fang, P. (2014). Authentic leadership, collective efficacy and group performance: an empirical study in China. Social Behavior and Personality, 42(6), 921-932. doi:10.2224/sbp.2014.42.6.921.

Zander, L., \& Romani, L. (2004). When nationality matters: a study of departmental, hierarchical, professional, gender and age-based employee groupings' leadership preferences across 15 countries. International Journal of Cross-Cultural Management, 4, 291-315.

Zhang, H., Everett, A., Elkin, G., \& Cone, M. (2012). Authentic leadership theory development: theorizing on Chinese philosophy. Asia Pacific Business Review, 18(4), 587-605.

\section{Submit your manuscript to a SpringerOpen ${ }^{\circ}$ journal and benefit from:}

- Convenient online submission

- Rigorous peer review

- Immediate publication on acceptance

- Open access: articles freely available online

- High visibility within the field

- Retaining the copyright to your article

Submit your next manuscript at $\gg$ springeropen.com 